\title{
TRÂNSFUGAS DE CLASSE SOCIAL E DE GÊNERO: TRAJETÓRIAS SOCIAIS DE EGRESSAS DE UM COLÉGIO PÚBLICO DE FLORIANÓPOLIS (SEGUNDA METADE DO SÉCULO XX)
}

\author{
TURNCOATS SOCIAL CLASS AND GENDER: TRAJECTORIES OF SOCIAL \\ FORMER STUDENT FROM A PUBLIC SCHOOL IN FLORIANÓPOLIS (SECOND \\ HALF OF THE TWENTIETH CENTURY)
}

\author{
VIEIRA, Letícia \\ leticia.vieira1990@gmail.com \\ Universidade do Estado de Santa Catarina - UDESC \\ DALLABRIDA, Norberto \\ norbertodallabrida@hotmail.com \\ Universidade do Estado de Santa Catarina - UDESC
}

\begin{abstract}
RESUMO O presente artigo tem por objetivo compreender as trajetórias sociais de três trânsfugas do Ensino Secundário do Colégio Estadual Dias Velho na década de 1950 , ou seja, mulheres que romperam as suas barreiras de classe social e de gênero por meio do êxito escolar. Esses trajetos sociais são compreendidos através dos indicadores origem sócio-familiar, percurso escolar e carreira profissional; e serão analisados a partir dos conceitos cunhados pelo sociólogo Pierre Bourdieu, em especial os conceitos de habitus e a visão polimorfa do capital. Tem-se por intuito perceber, a partir da análise destes indicadores, as posições ocupadas por estas mulheres nos diversos campos de que fizeram parte ao longo de suas trajetórias sociais. Toma-se como aporte teórico também os estudos de Bernard Lahire, que tornam possível compreender os mecanismos e estratégias criados no interior das famílias desprovidas de um relevante volume de capitais para desenvolver nos filhos disposições que tornem possível o sucesso escolar e o alcance de melhores posições nos campos econômico e social.
\end{abstract}

PALAVRAS-CHAVE: Trajetória social. Trânsfugas. Ensino secundário. Escola pública.

ABSTRACT This paper aims to understand the social trajectories of three turncoats of Secondary Education on Colégio Estadual Dias Velho in 1950, in other words, women who broke their barriers of class and gender through academic achievement. These paths are understood through the social indicators: socio-family origin, educational background and career; and will be analyzed from concepts created by 
sociologist Pierre Bourdieu, especially the concepts of habitus and capital's polymorphous vision. It has as purpose realizing, from the analysis of these indicators, the positions occupied by these women in different fields that they were part along their social trajectories. Are taken as theoretical support the studies of Bernard Lahire that make it possible the understanding of the mechanisms and strategies found within families deprived of a significant amount of capital to develop on their children provisions that permit school success and achievement of better positions in economic and social fields.

KEYWORDS: Social trajectory. Turncoats. Secondary school. Public school.

\section{INTRODUÇÃO}

Instituído em Florianópolis, em 1950, o Colégio Estadual Dias Velho (CEDV) foi a primeira instituição a oferecer Ensino Secundário público, gratuito e laico na capital catarinense. Até essa data, esse nível de escolarização era oferecido somente por duas instituições de caráter elitista e confessional e distintas em gênero: o Colégio Coração de Jesus, dirigido pelas Irmãs da Divina Providência e especializado na educação das filhas, moças distintas, e o Colégio Catarinense, dirigido por padres jesuítas e frequentado pelos jovens moços pertencentes às elites. Neste contexto, a oferta dos dois cursos previstos pela Reforma Capanema para o ciclo colegial - o curso clássico, que focava nas humanidades clássicas e modernas, e o curso científico, que colocava em relevo as ciências exatas e tecnológicas - em uma instituição gratuita e que funcionava no período noturno, configurava-se como uma proposta atraente e viável para os jovens que não tinham condições financeiras para arcar com as mensalidades dos colégios católicos que ofereciam este nível de ensino e/ou para aqueles que tinham necessidade de trabalhar no contraturno escolar. O CEDV também era considerado uma instituição inovadora por ser coeducativo, colocar em prática um ensino menos regulador e ter um corpo docente qualificado, composto por profissionais selecionados através de concursos públicos e, por isso, marcados pela "diversidade ideológica, religiosa e cultural" (DALLABRIDA, 2011, p. 152).

A criação do ciclo colegial no interior do Instituto de Educação Dias Velho da capital catarinense enquadra-se num momento de expansão expressiva do ensino secundário brasileiro, impulsionado pela Reforma Capanema. Em Santa Catarina, além do Colégio Estadual Dias Velho, no final dos anos 1940, foram criados o 
Colégio Pedro II, localizado em Blumenau, e o Colégio Estadual de Lages, que abriram as portas ao ensino secundário especialmente para as classes médias e para mulheres. Deve-se considerar que este momento histórico foi diferenciado por atribuir novos ares à função social da mulher. Estas novas concepções alavancadas pela atmosfera do pós-Segunda Guerra Mundial, que abandonava alguns preceitos de submissão feminina, passaram a permitir à mulher a conquista de novos espaços, atribuindo à sua figura funções que transcendiam o papel de "boa mãe e esposa" (MARTINI, 2011, p. 62). Desta forma, o oferecimento do ensino secundário público, gratuito, laico e coeducativo no Colégio Estadual Dias Velho, a partir da década de 1950, concorreu para um avanço significativo da inclusão das mulheres neste nível de ensino, que oportunizava o ingresso no ensino superior.

É neste espaço-tempo que se inserem as trajetórias sociais de Adélia, Lúcia e Lourdes ${ }^{1}$, mulheres provenientes de famílias que não pertenciam a grupos sociais privilegiados, que transcenderam os limites impostos por suas origens sociais e realizaram percursos escolares prolongados e carreiras profissionais de êxito. Esta análise tem como intuito focalizar as trajetórias dessas agentes sociais, que fizeram parte de uma pesquisa que investigou as trajetórias sociais de vinte e quatro alunas egressas do Colégio Estadual Dias Velho na década de 1950. Menciona-se aqui o fato de que em meados do século $X X$ era muito raro que mulheres de classes desfavorecidas concluíssem o ensino secundário, conforme é evidenciado pela trajetória destas egressas. Buscamos perceber, assim, as estratégias traçadas por estas ex-alunas e seus familiares para driblar o déficit ocasionado pela ausência ou baixo nível capitais herdados e conquistar o acesso à escolarização média.

As trajetórias sociais dessas mulheres foram estudadas, inicialmente, a partir da análise das respostas obtidas através da aplicação de um extenso questionário com questões abertas e objetivas, enviado para formadas no Colégio Estadual Dias Velho. No entanto, as três egressas que integram as análises desse artigo foram escolhidas devido à relevância de suas trajetórias sociais, evidenciadas a partir dos marcadores sociais gênero e classe social, e foram investigadas por meio da realização de uma entrevista semiestruturada, cujo objetivo consistiu em obter informações mais detalhadas acerca dos trajetos trilhados por essas ex-alunas. A

\footnotetext{
${ }^{1}$ Para preservar a identidade das entrevistadas, os nomes aqui utilizados são fictícios.
} 
relevância de fontes que permitam uma microanálise, tais como as utilizadas neste estudo, deve-se ao fato de que, segundo Martini (2011, p. 99), "a análise de contextos mais particulares revelam redes de interdependência (familiares, escolares, políticas, religiosas, entre outras) que explicam fatos sociais, como por exemplo, a mobilidade social [...]", em casos como o dessas egressas.

A trajetória social é constituída por "relações que se dão entre agentes e forças presentes no campo" (MONTAGNER, 2007, p. 254). Segundo Bourdieu (2003, p. 206), campo é um "microcosmo social" que tem jogos, regras e capitais específicos, tendo autonomia relativa. Dallabrida (2011, p. 146) afirma que "os campos são marcados, necessariamente, por disputas pelo controle e legitimação dos bens produzidos e classificados, de forma que no seu interior há relações de força entre 'posições dominantes' e 'posições inferiores'". Nesta direção, no presente estudo, intentamos compreender as trajetórias sociais a partir da análise das interrelações entre a origem sócio-familiar, o percurso escolar e a carreira profissional dos agentes sociais. As posições ocupadas por esses agentes no campo levam em conta, além do capital econômico, sobremaneira outras formas de capital elaboradas por Pierre Bourdieu para flagrar as desigualdades escolares e culturais, quais sejam: capital cultural, capital simbólico, capital social e capital informacional.

Para Bourdieu, o capital consiste na transmissão feita principalmente na atmosfera sócio-familiar e mais de forma indireta do que direta, de modo que os herdeiros adquirem disposições socialmente construídas. Assim, no seio familiar o agente social herda "um certo capital cultural e um certo ethos, sistema de valores implícitos e profundamente interiorizados, que contribui para definir, entre coisas, as atitudes face ao capital cultural e à instituição escolar" (BOURDIEU, 1998a, p. 42). Em sua análise, o sociólogo francês define três diferentes estados para o capital cultural, de maneira que este pode ser internalizado no estado incorporado, por meio de crenças, valores, hábitos, condutas disposições; no estado objetivado, via apropriação de bens culturais como livros e obras de arte; ou, ainda, no estado institucionalizado ou capital escolar através da posse de títulos e certificados escolares (BOURDIEU, 1998c). O capital cultural incorporado é considerado um habitus, isto é, um sistema de disposições duráveis estruturadas a partir do meio social que vinculam "as práticas e os bens de um agente singular ou de uma classe 
de agentes" (BOURDIEU, 1996, p. 21), sendo definido por Bourdieu (1996, p. 22) como:

princípios geradores de práticas distintas e distintivas [...] esquemas classificatórios, princípios de classificação, princípios de visão e de divisão e gostos diferentes. Eles estabelecem as diferenças entre o que é bom e mau, entre o bem e o mal, entre o que é distinto e o que é vulgar etc., mas elas não são as mesmas. Assim, por exemplo, o mesmo comportamento ou o mesmo bem pode parecer distinto para um, pretensioso ou ostentatório para outro e vulgar para um terceiro [grifo nosso].

Para flagrar desigualdades sociais, especialmente nas carreiras profissionais e em trajetórias de agentes sociais que integraram às elites, Bourdieu cria o conceito de capital social, que é constituído por uma rede de relações sociais durável e útil à manutenção e ampliação dos capitais - ainda que, para isso, exija-se do sujeito um trabalho de instauração e manutenção (DALLABRIDA, 2012). O capital simbólico, por sua vez, é definido pelo autor como responsável por dar visibilidade aos sujeitos que dele dispõem - bem como a títulos, certificados ou instituições - conferindo prestígio ao indivíduo dentro de dado grupo social e atuando, consequentemente, como mecanismo de distinção nos campos. Em verdade, há efetivamente "efeitos simbólicos" em diferentes campos do espaço social, que têm capitais, regras e jogos específicos.

Na perspectiva bourdieusiana, o êxito escolar e socioprofissional dependem do acúmulo e inter-relação de diferentes capitais, de maneira que os sujeitos pertencentes às classes sociais desfavorecidas têm desvantagem no mercado profissional e social. Contudo, contrário ao "determinismo bourdieusiano", Bernard Lahire (2004) desenvolveu estudos de cunho microssociológico, a partir dos quais constatou ser possível a alunos provenientes de camadas sociais desfavorecidas atingirem êxito escolar e profissional na mesma medida que indivíduos nascidos em meios sociais favoráveis, desde que sejam mantidas condições familiares e/ou sociais que favoreçam o desenvolvimento de características valorizadas socialmente e pelas instituições escolares. Ele argumenta que, ainda que as condições econômicas e culturais sejam, indubitavelmente, fatores que exercem fortes influências sob a relação do sujeito com o saber, a presença dos capitais só faz sentido e surte efeitos quando se encontram formas adequadas para a transmissão dos mesmos. 
Os instigantes conceitos bourdieusianos que permitem compreender as desigualdades sociais movimentadas na esfera microssociológica, tal qual a concebe Bernard Lahire, são a clave teórica construída para ler as trajetórias sociais das três egressas do Colégio Estadual Dias Velho. Estas mulheres, objetos do presente artigo, são consideradas nesta leitura como trânsfugas, isto é, agentes sociais que, por meio do êxito escolar, romperam as suas barreiras de classe social e de gênero.

\section{UMA ASSÍDUA LEITORA AJUDADA POR MEDIADORAS SOCIAIS}

A entrevista realizada com Adélia ocorreu em sua residência, localizada em uma área relativamente privilegiada da cidade de Florianópolis ${ }^{2}$, onde residem, sobretudo, famílias de classes médias e médias altas. A casa, cuidadosamente organizada e decorada com fotos da família e objetos relacionados à religião católica, deixava transparecer, em seus detalhes, muito sobre a trajetória de vida desta egressa. Na mesa central da sala de estar encontrava-se uma bíblia aberta e, nos demais móveis, estavam também dispostas algumas imagens de santos e anjos. Em um destes móveis havia um quadro de formatura do marido de Adélia - já falecido. Junto a este quadro, troféu que atestava o sucesso escolar do marido. Estavam também posicionadas algumas fotografias da família. Cada detalhe da residência reflete a trajetória desta trânsfuga, cuja história é hoje marcada principalmente por sua dedicação à família.

Adélia nasceu em 1932 na cidade de Canoinhas (Santa Catarina) e permaneceu nesta pequena cidade até a idade de oito anos, quando migrou para Florianópolis. Durante o período em que viveu em sua cidade natal, teve sua infância marcada por dois "rompimentos biográficos" marcantes: a morte de sua mãe, em 1937, quando tinha apenas cinco anos de idade, e a infecção de seu pai

\footnotetext{
${ }^{2} \mathrm{O}$ local onde as trânsfugas aqui analisadas residiam à época das entrevistas consiste em um possível indicativo da posição social que ocupavam no campo, uma vez que, por serem percebidos na cidade como locais onde residia um seleto grupo de sujeitos, funcionavam como "propriedade distintiva". Segundo Bourdieu (1996, p. 23), uma propriedade só "se torna uma diferença visível, perceptível, não indiferente, socialmente pertinente, se ela é percebida por alguém capaz de estabelecer a diferença".
} 
pelo mal de Hansen, fato este que fez com os dois fossem obrigados a abandonar a chácara em que viviam na cidade natal para tornarem-se internos de estabelecimentos destinados ao tratamento de hansenianos e de observação dos filhos de infectados. Fato ocorrido ainda no início de sua infância, este internamento compulsório tornou-se um divisor de águas na trajetória social desta ex-aluna, pois, ainda que não fosse portadora da doença do pai, o desconhecimento médico acerca da maneira como ocorria o contágio fez com que acabasse por ser também retirada do contexto familiar e internada em um educandário destinado a filhos de pais hansenianos, onde a levavam a centros médicos para realizar exames periódicos. Após o internamento do pai de Adélia, a situação financeira da família agravou-se, uma vez que ambos passaram a ser sustentados pelos cofres públicos, pois não tinham casa, bens ou quaisquer valores que pudessem destinar à sua subsistência.

Filha única e alvo de grande apreço por parte de seu pai - um homem considerado muitíssimo inteligente e que havia concluído o ensino primário em uma escola confessional privada e bem conceituada na cidade de Canoinhas - Adélia foi iniciada nas letras muito cedo. Segundo ela, seu pai era uma referência na cidade onde vivia, onde era constantemente consultado pelos lavradores de terras para que realizasse cálculos referentes aos hectares de terras, plantação e colheitas. Preocupado com a escolarização da filha, em seu aniversário de seis anos, o pai a presenteia com a cartilha com a qual ele aprendera a ler e passa a ensinar à Adélia as lições de primeiras letras e números, de forma que, ao entrar no ensino primário do grupo escolar do Educandário Santa Catarina, ela já sabia ler e contar com destreza e diferenciava-se das demais colegas. Diz ela:

\footnotetext{
[...] ele [o pai], apesar de a gente está lá naquele interior, ele fazia questão, assinava revistas, que chegavam muito atrasadas, jornal também chegava atrasado, mas chegava. O almanaque então era sagrado! Naquela época sempre se recebia também. $E$ tudo isso ele lia e eu também lia. Ele foi me ensinando muito. E a leitura eu tirava sempre bem porque tive esse princípio. Desde os seis anos eu estava acostumada. Mesmo quando eu era pequena ele fazia as leituras, fazia leituras da bíblia, fazia leituras instrutivas... Eu me lembro que o primeiro livro, então eu lia de fio a pavio o livro que ele me deu, que foi a cartilha dele [...] o hábito eu herdei acho que do papai (VIEIRA, 2011, p. 04).
}

Ao analisar a origem social e o início do percurso escolar desta egressa fica claro que o constante incentivo à leitura, inicialmente feito pelo pai e depois 
retomado por aquelas que passaram a ser responsáveis por sua educação e escolarização, foi interiorizado e permitiu a ela que agregasse ao seu habitus de classe popular uma disposição reservada principalmente às moças de elite, o que figurou como um aspecto favorável aos seus estudos: o domínio da cultura escrita. A incorporação desta disposição de gosto pela leitura e pelos estudos foi o primeiro fator favorável ao sucesso escolar para esta egressa, vindo a figurar como característica de destaque em seu percurso escolar e sendo o motivo pelo qual foi incentivada pela irmã ${ }^{3}$ diretora do educandário a prosseguir nos estudos e ingressar no ginasial, distinguindo-se das demais alunas, que não seguiram o mesmo caminho.

Adélia não fazia parte de uma família com elevado capital econômico, tampouco havia sido criada em uma família de grande prestígio social ou munida de amplas redes de relações sociais das quais poderia beneficiar-se, mas contou com os esforços do pai para transmitir por vias familiares e fazer multiplicar com auxílio da escola, sua única herança: um modesto volume de capital cultural. Não é possível, contudo, analisar a trajetória social desta ex-aluna tomando como base apenas o capital cultural da família e seu percurso escolar exitoso. Neste sentido, faz-se necessário mencionar que, no primeiro momento da trajetória social da egressa, que compreende o percurso escolar e se passa, portanto, no campo das instituições de ensino, o capital cultural tem um maior valor simbólico agregado. Contudo, tendo concluído o curso ginasial no CEDV e, tendo em vista sua necessidade de começar a trabalhar para a própria subsistência, fez-se necessário, além do capital cultural, a movimentação de outros capitais que Adélia não possuía. Passou a ser decisiva, neste sentido, a atuação de mediadores sociais que a auxiliassem e permitissem que fosse em frente.

A trajetória social desta egressa contou com a presença de duas importantes mediadoras sociais, mulheres que, percebendo a desenvoltura e capacidade que possuía, colocaram seus capitais em movimento nos campos para propiciar seu progresso escolar e, posteriormente, profissional. A primeira destas mediadoras foi a irmã diretora Joaquina Feuser, que, fazendo uso do capital informacional ${ }^{4}$ que

\footnotetext{
${ }^{3}$ Freira de uma congregação religiosa ligada à Igreja Católica catarinense.

${ }^{4}$ Bourdieu (1998a, p. 45), denomina "capital de informações" - ou capital informacional, como aqui denominado - o conjunto de informações sobre o funcionamento da escola, do sistema universitário e
} 
detinha, incentivou a egressa a dedicar-se aos estudos e tentar o ingresso no Colégio Estadual Dias Velho. Incentivando-a também para além do campo escolar, essa irmã ensinava-a ofícios que considerava importantes e, colocando em movimento o capital social de que dispunha, indicou-a ao seu primeiro emprego como secretária da esposa do então governador do Estado de Santa Catarina Irineu Bornhausen. A segunda mediadora social apontada pela egressa foi Marieta Bornhausen, primeira dama catarinense, por quem a egressa foi chamada para trabalhar na Legião Brasileira de Assistência (LBA) e, após alguns anos de atuação, foi também incentivada a fugir da instabilidade dos cargos comissionados e políticos e buscar ingresso no funcionalismo público, o que a levou a prestar concurso no ano de 1955 e ingressar no serviço público estadual.

No dia 25 de março de 1955 ocorreu a solenidade oficial da instalação da Faculdade Catarinense de Filosofia e, logo, tiveram início as aulas do curso de Letras Clássicas. Ao buscar relembrar este período, Adélia afirma que já nos primeiros dias de aula as dificuldades começaram a se fazer presentes. Os obstáculos enfrentados pela egressa - dificuldades de locomoção e horário, que se agravaram principalmente após o casamento - fazem com que a trajetória universitária de Adélia seja logo interrompida. Ainda que contasse com disposições que facilitavam o domínio da cultura escrita, o que, sem dúvidas, facilitaria sua trajetória universitária no Curso de Letras Clássicas, Adélia é forçada a abrir mão dos estudos e passa a se dedicar ao emprego e, de forma especial, à família. $\mathrm{O}$ discurso desta egressa acerca de sua trajetória social torna possível percebermos os limites de expansão deste "espaço dos possíveis" (BOURDIEU, 2004, p. 307). Adélia tinha poucas possibilidades de prosperar nos campos escolar e profissional, mas contou com certo grau de capital cultural, herdado via socialização paterna e com o auxílio de mediadoras sociais que a auxiliaram na busca por novas e melhores posições nestes campos. Contudo, ainda que tivesse conquistado os espaços e disposições necessárias para que pudesse quebrar a lógica social em que se encontrava por condição sociofamiliar, há um momento em que o avanço desta trânsfuga é estancado. 
Embora Adélia tenha desenvolvido no meio familiar e no internato algumas das disposições necessárias para o ingresso no ensino superior e o sucesso profissional, as limitações advindas do baixo volume de capitais herdados e as condições relacionadas às questões de gênero à época fizeram com que a egressa desistisse e abrisse mão de sua vida acadêmica em favor da carreira do marido. Ela retorna então suas aspirações para aquelas possibilidades que se encontram dentro de suas condições, "tornando-se inconscientemente cúmplice dos processos que tendem a realizar o provável” (BOURDIEU, 1999, p. 91).

\section{3 “AUTOMOTIVAÇÃO” E CONCENTRAÇÃO DE INVESTIMENTOS}

A entrevista realizada com a egressa Lourdes, formada no Curso Clássico do Colégio Estadual Dias Velho no ano de 1957, ocorreu também em sua residência, um amplo apartamento localizado em um dos bairros mais nobres da cidade de Florianópolis, onde se agrupa uma parcela estritamente selecionada da população da cidade. A sala onde ocorreu a conversa era ampla, arejada, iluminada e contava com belos móveis, cuidadosamente dispostos. A atmosfera evidenciava a forte formalidade do encontro, fruto do habitus professoral da entrevistada, evidenciado a partir de uma hexis corporal diferenciada: a egressa expressava-se muitíssimo bem e demonstrava uma natural elegância nos gestos.

Nascida na cidade de Florianópolis em 1939, Lourdes residiu desde a infância em Blumenau (Santa Catarina), onde seu pai, funcionário público do Banco do Brasil, atuava como bancário, proporcionando-lhe o que Lahire (2004, p.24) denominou "economia doméstica estável". Filha única em uma família de classe média, Lourdes sempre foi alvo de todos os investimentos dos pais, que não mediam esforços para que a mesma pudesse ter uma vida confortável e livre de privações. Buscando investir na vida escolar da única filha, o pai, que era espírita, ao percebê-la entrando em idade escolar, busca colocá-la em uma escola privada confessional da cidade de Blumenau, mas tem sua tentativa de matrícula rejeitada devido ao fato de a família não seguir a doutrina católica - o que não foi visto com bons olhos pelas irmãs que conduziam o colégio. Impedida de frequentar o colégio privado da região foi então matriculada no Grupo Escolar Luiz Delfino, onde concluiu o curso primário. 
Desde os primeiros anos de socialização, Lourdes foi incentivada a dedicar-se aos estudos e desenvolveu disposições e práticas favoráveis ao sucesso escolar. Seus pais, detentores de certo nível de capital escolar- ambos haviam concluído o curso complementar, o que, para a época, era distintivo - contando com a ajuda de uma tia que era professora e residia junto à família, alfabetizaram-na antes do ingresso no curso primário, bem como proporcionaram-lhe aulas de francês e incentivavam-na à leitura, presenteando-a com gibis e livros, despertando na menina a curiosidade e o desejo pelos livros. No discurso da ex-aluna, fica evidente, sobretudo, a importância do incentivo do pai para a construção de uma disposição de gosto pela leitura:

Eu tirava sempre notas boas e meu pai sempre me estimulou à leitura, principalmente quando era pequena. Tinha gibis, gibizinhos, e os gibis tinham continuação na outra semana... O gibi era semanal e vinha então, continuava na semana seguinte. E eu ficava ansiosa que ele trouxesse a nova edição para eu ler a continuação das historias de gibis (VIEIRA, 2012a, p. 01).

Lahire (2004) dá ênfase à importância da intervenção e do investimento familiar para que o ambiente doméstico crie uma atmosfera favorável à construção de disposições que concorram ao sucesso escolar. No caso de Lourdes, além de um constante incentivo à prática de leitura, que proporcionou grande familiaridade com a cultura escrita, a egressa recebeu dos pais e familiares bons sentimentos a respeito da escola e do saber. A partir do momento em que o aprendizado e as práticas de leitura e de estudos configuravam-se como momentos de socialização familiar e ocasiões em que recebia o afeto dos pais e da tia, ensinava-se a ela que aprender era algo positivo, diminuindo-se, assim, as possíveis tensões da criança frente à escola (LAHIRE, 2004, p. 20).

Após a conclusão do curso primário, Lourdes ingressou no Curso Ginasial do Colégio Pedro II, estabelecimento de ensino público e gratuito localizado em Blumenau. Segundo essa ex-aluna, a aprovação no exame de admissão - artefato de seleção cuja aprovação na época, era imprescindível para o acesso ao ensino secundário -, foi marcada por muitas tensões, exigindo grande dispêndio de tempo e esforços. O ingresso dela no Colégio Estadual Dias Velho ocorreu em 1951, quando, devido à transferência de seu pai para Florianópolis, a família obrigou-se a mudar para a capital catarinense. Segundo a egressa, a escolha pelo Colégio Estadual 
Dias Velho deu-se, sobretudo, pelo fato de já terem passado pela experiência de ter a matrícula rejeitada em uma escola confessional privada, de forma que seus pais não cogitaram transferi-la para o Colégio Coração de Jesus, optando então pelo ensino público e laico. A egressa ressaltou, ainda, que a qualidade do ensino ministrado no Colégio Estadual Dias Velho era equivalente ao do Colégio Pedro II ambos eram colégios mantidos pelo governo estadual que detinham capital simbólico no subcampo do ensino secundário catarinense - de modo que a transferência se deu sem problemas.

Desde jovem, Lourdes nutria o sonho de prestar vestibular para o Curso de Matemática. Contudo, tolhida pela escassez de ofertas de cursos superiores na capital catarinense até a década de 1960, quando foi criada a Universidade Federal de Santa Catarina, e ciente de que, por questões de gênero, não poderia sair de Florianópolis para frequentar curso superior em outra cidade, abdicou de ingressar no curso científico, que a direcionaria para as ciências exatas, e optou pelo curso clássico, tendo em vista o ingresso no Curso de História na Faculdade de Filosofia de Florianópolis, alternativa esta que figurava como uma opção menos atrativa e distante de suas expectativas, mas que se aproximava mais de suas reais possibilidades.

Limitando-se ao "espaço dos possíveis" (BOURDIEU, 2004, p. 307) que se configurava por sua condição de mulher, Lourdes ingressou no Curso de História da Faculdade de Filosofia no ano de 1957. Iniciou-se, então, sua trajetória como docente: antes mesmo de concluir o Curso de História, em 1960 a egressa passa a dar aulas no Colégio Estadual Dias Velho, dividindo espaço no campo profissional com aqueles que haviam sido seus professores poucos anos antes. No ano seguinte, Lourdes conclui esse curso superior e, em 1972, presta concurso para ingressar como docente na recém fundada Universidade Federal de Santa Catarina, vindo a ser aprovada e passando a fazer parte, então, da "elite intelectual" florianopolitana.

A atual situação econômica privilegiada desta trânsfuga de classe não se deve, contudo, apenas ao seu triunfo profissional como docente. A carreira de sucesso angariada pela egressa, ainda que pudesse oferecer certo status econômico e social, por tratar-se de uma ocupação como professora de nível superior em uma universidade pública, tornou-se mais rentável a partir de uma 
aliança matrimonial favorável à manutenção e multiplicação dos capitais que até então dispunha: seu esposo era auditor fiscal da Receita Federal, carreira de grande prestígio e cuja remuneração proporcionava, já naquela época, um relevante nível de capital econômico. As escolhas do casal, da mesma forma, concorreram também para uma maior acumulação de capitais, conforme ela rememora:

Financeiramente eu melhorei, lógico. Porque eu me casei, meu marido era auditor fiscal da Receita, tinha um alto salário... Então tudo isso não é só da minha parte, mas da dele também. Eu tive só uma filha, então tudo isso levou a um nível econômico e social melhor (HUBENER, 2012, p. 07)

A disposição de desejo pelos estudos, construída na infância a partir da socialização familiar e fortalecida pela passagem por estabelecimentos de ensino público de qualidade, fez-se presente durante toda a trajetória de Lourdes, de forma que, enquanto professora da Universidade Federal de Santa Catarina (UFSC), a egressa prosseguiu aperfeiçoando-se, concluindo cursos de pós-graduação em nível de especialização e de mestrado. Pode-se afirmar que o sentimento que a motivava a estudar - que por diversas vezes durante a entrevista é denominado pela egressa de "automotivação" - nada mais é do que expressão de um habitus ou uma disposição que, enquanto "produto incorporado de uma socialização" (LAHIRE, 2004 , p. 28), surtiu seus efeitos durante toda a trajetória da egressa, mesmo nos momentos em que deixou de existir intervenção direta dos pais. Em outras palavras, os "sistemas de preferências" adquiridos a partir da socialização familiar, passaram a orientar diretamente "seus comportamentos, suas condutas, suas escolhas e seus gostos" (BOURDIEU; CHARTIER, 2010, p.57-9), principalmente no que dizia respeito à escolarização, conduzindo-a ao sucesso escolar e profissional.

Lourdes pertencia a uma família com volume mediano de capitais cultural e econômico e pouco volume de capital social. Contudo, fez-se valer a estratégia familiar de concentrar seus investimentos em uma única filha, que deteve todos os privilégios de uma configuração familiar onde se tem um único herdeiro. Ainda que quando jovem não pertencesse a uma elite econômica ou intelectual, ela pôde dedicar-se exclusivamente aos estudos até a conclusão do Ensino Secundário no Colégio Estadual Dias Velho, pois contava com o apoio financeiro da família, o que não era uma realidade comum a todas as jovens que cursavam esse nível de escolarização naquela instituição no período pesquisado. Deve-se destacar ainda 
que, embora contasse com alguns privilégios próprios de sua configuração familiar, Lourdes sofreu também com limitações advindas de sua condição de mulher: não pôde cursar a faculdade que desejava por estar limitada aos cursos oferecidos na cidade onde residia - ainda que tenha vindo, mais tarde, a encarar tal falta de opção com certo otimismo, considerando-se profissionalmente realizada.

Por outro lado, para além das limitações próprias da situação das mulheres à época, pôde-se perceber a importância de uma aliança matrimonial favorável à manutenção e multiplicação de capitais uma vez que muito do alcançado pela egressa no que diz respeito a questões econômicas e sociais, deveu-se à estabilidade proporcionada pela junção dos benefícios do seu excelente salário como professora universitária, bem como do status do marido.

Segundo Bourdieu (1996, p. 29) "é preciso construir o espaço social como estrutura de posições diferenciadas, definidas, em cada caso, pelo lugar que ocupam na distribuição de um tipo específico de capital". Menciona-se, nesta direção, que ainda que a trajetória social desta egressa não permita defini-la como uma trânsfuga radical, visto que em sua infância desfrutou dos benefícios de ser a única filha em uma família pertencente à classe média, o volume de capitais acumulado por Lourdes ao longo de sua trajetória permitiu que esta alcançasse uma melhor posição no campo em que se movimentava, passando esta a fazer parte da elite da cidade de Florianópolis. É importante ressaltar que quando a denominamos pertencente à elite desta capital, temos em mente a configuração de um campo onde as famílias abastadas são compostas, sobretudo, por funcionários públicos que ocupam cargos elevados e empresários, não sendo fator comum neste espaço social a presença maciça de elites agrárias ou fabris. Levou-se em consideração para esta análise, portanto, os "princípios de diferenciação" próprios do campo analisado.

\section{A ADVOGADA QUE SE DEDICOU AO LAR}

A entrevista realizada com a egressa Lúcia ocorreu em sua residência, uma ampla casa localizada em uma área muitíssimo privilegiada do centro de Florianópolis. A residência, ainda que discreta e pintada em tons sóbrios, denunciava sua imponência em meio a prédios e conceituados estabelecimentos de 
saúde de Florianópolis. A conversa ocorreu na sala de jantar da sua casa, um amplo cômodo bem arejado e mobiliado, onde era possível encontrar um grande número de fotos da família da egressa.

Lúcia nasceu em 1933 na cidade de Porto Alegre, onde residiu durante parte considerável de sua infância. Integrante de uma família com cinco filhos e cujo pai era funcionário da Companhia Telefônica de Porto Alegre, pôde desfrutar de alguns privilégios educacionais, ainda que estes dependessem de certo esforço por parte de seus pais: desde os primeiros anos de escolarização, ela e seus irmãos frequentaram os melhores colégios de Porto Alegre e Florianópolis, entre eles 0 Colégio Coração de Jesus e o Colégio Catarinense. Sendo a filha mais nova de seu núcleo familiar, essa egressa tinha cinco anos quando, por ocasião do afastamento do pai da Companhia Telefônica de Porto Alegre, devido a uma acusação política que recebera e nunca fora comprovada, relacionada ao governo de Getúlio Vargas, mudou-se para Florianópolis para que o pai trabalhasse na Empresa Telefônica.

A egressa relata que, embora as mensalidades dos educandários que ela e os irmãos frequentavam fossem altas e o pai fosse um profissional cuja situação financeira não permitia "luxos", nenhum membro da família fora contemplado com bolsas. As dificuldades, contudo, faziam-se presentes, pois, segundo ela: "às vezes as freiras, a tesoureira, mandavam perguntar e falar. Então às vezes é que a gente ficava realmente vendo a situação [...]" (VIEIRA, 2012b, p. 02). Por outro lado, mesmo após a inauguração do CEDV e a oferta de ensino secundário gratuito na instituição, a transferência passou a ser considerada uma opção viável apenas após algumas dificuldades de aprendizagem da egressa fazerem-se presentes, fato que figurou como um dos motes para que a aluna tentasse ingresso no CEDV após concluir o curso Ginasial no Colégio Coração de Jesus, cursando um ano do Curso Normal na instituição e, posteriormente, transferindo-se para o Curso Científico.

A hipótese de que o "sucesso escolar" de Lúcia decorreu do fato de seus pais priorizarem a educação dos filhos e concentrarem a maior parte do capital econômico que detinham em investimentos para este fim é evidenciada a partir da fala da egressa, quando afirma que "[...] nós não tivemos casa. Em Porto Alegre até tínhamos, aqui não comprou, pagava aluguel. E, com o trabalho dele [do pai] na 
Telefônica, ele sempre procurou custear, realmente. Minha mãe era dona de casa" (GOMES, 2012, p. 02). Nesta direção, fica evidente que, ainda que seus pais não detivessem alto nível de capital econômico, encontraram vias de transmissão e de reconversão deste em capital escolar a partir de um superinvestimento na educação dos filhos. Como resultado desta grande dedicação tem-se o fato de que todos os irmãos de Lúcia seguiram nos estudos, concluindo cursos universitários de prestígio e conquistando espaços de destaque nos campos social e profissional. Seguindo esta tendência, a egressa prestou vestibular e ingressou no curso de Direito da UFSC, concluindo a graduação apenas em 1962, devido a algumas interrupções e obteve o registro na Ordem dos Advogados de Santa Catarina, mas não atuou profissionalmente.

Nesta direção, é interessante destacar o fato de que a dificuldade em inserirse no mercado de trabalho é um dos fatos de maior destaque na trajetória social de Lúcia. Ainda que a egressa tenha concluído um dos cursos de maior capital simbólico no subcampo de ensino universitário de Florianópolis, não encontrou vias de tornar rentável o capital escolar acumulado. No primeiro momento da trajetória desta ex-aluna, a escolha pela família prevaleceu, uma vez que a egressa relata que, devido ao fato de ter contraído matrimônio quando estava no segundo ano do curso de Direito, teve de trancar a matrícula por alguns anos. Ela relata que:

[...] aconteceu que quando eu estava no segundo eu casei, nós fomos para o interior, ai eu fui obrigada a trancar a matrícula. Aí voltamos em sessenta, eu fiz os dois anos, mas me arrependi. Porque eu acho que eu deveria ter esperado, como depois eu esperei dez anos pra fazer novamente o estágio, mas engravidei outra vez e fiquei, nós tivemos sete [filhos] e eu fui cuidar da pequena (VIEIRA, 2012b, p. 04).

Após dez anos de dedicação ao lar e à família, Lúcia busca ingressar no mercado de trabalho, firmando parceria com colegas formadas em Direito. Contudo, a demanda de trabalho familiar advinda da opção da egressa de ter um grande número de filhos tolhe sua vontade de consolidar carreira, fazendo com que, ao

\footnotetext{
${ }^{5}$ Pode-se considerar, neste sentido, que a transferência do pai em decorrência de acusações de natureza política configurou-se como um "rompimento biográfico" para esta egressa, uma vez que a situação social da família modificou-se radicalmente (devido ao afastamento da família e amigos) e a situação financeira fora levemente agravada, devido a impossibilidade de adquirem imóvel próprio na capital.
} 
contrário das outras colegas com que manteve sociedade por este curto período de tempo, acabasse por abandonar a atividade profissional:

[...] Eu tentei advogar com mulheres, nós saímos na época para advogar, tentei, comecei, mas realmente foi... Era muita criança, naquela época tinha filho, né? Apesar de que tem pessoas que com filho conseguiram trabalhar, se aposentar e ter carreira, fazer carreira [...] até minhas colegas que estavam conosco saíram. Uma deu aula no [Colégio] Catarinense, só uma ficou sozinha advogando, outra fez concurso, outra também encaminhou para o concurso público [...] (VIEIRA, 2012b, p. 04).

A privilegiada situação econômica e social da egressa não fora, contudo, significativamente prejudicada pelo abandono da carreira. Casada com um ex-aluno do Colégio Catarinense, médico e vinculado à maçonaria, Lúcia relata nunca ter tido dificuldades financeiras devido ao esforço do marido. É importante destacar a importância da aliança matrimonial firmada pela egressa, uma vez que, ainda que seu esposo não tivesse uma origem social privilegiada, encontrou, a partir da apropriação do ensino de qualidade recebido no Colégio Catarinense e, posteriormente, no Curso de Medicina, vias de converter o capital escolar que possuía em capital econômico e social, podendo oferecer uma vida de conforto à esposa e aos sete filhos.

Lúcia fazia parte de uma família de classe média que, devido ao grande número de integrantes, tinha dificuldades em manter o custeio da escolarização dos filhos. No entanto, a importância dada pelos pais à escolarização e, certamente, o capital cultural do pai - contador -, fez com que todos os filhos concluíssem os estudos e ingressassem em bons cursos universitários. Ao contrário das demais egressas cujas trajetórias sociais são analisadas neste escrito, que atuaram profissionalmente e obtiveram carreiras exitosas, a aliança matrimonial de Lúcia e sua opção por dedicar-se ao cuidado dos filhos acaba por ser o fator que torna possível a superação da condição econômica e social de seu núcleo familiar de origem. Assim, é a partir do sucesso profissional do marido que essa ex-aluna conquista novas e melhores posições nos campos econômico e social.

\section{ANOTAÇÕES FINAIS}


A análise da trajetória social das trânsfugas aqui estudadas torna possível a compreensão dos efeitos e da importância de um ambiente de socialização familiar que concorra ao desenvolvimento de um habitus de desejo pelos estudos e à construção de disposições favoráveis ao sucesso escolar. Durante o período de escolarização, no caso das egressas Adélia e Lourdes, a situação de êxito esteve intimamente ligada à motivação e à concentração dos investimentos familiares. Por serem filhas únicas, essas mulheres foram alvos de todas as estratégias e dedicação dos pais, o que fez com que se percebessem investidas de grande importância e se dedicassem com afinco às obrigações escolares, mesmo quando deixou de haver vigilância por parte de seus responsáveis. No caso Lúcia, o sucesso escolar esteve vinculado, especialmente, ao investimento econômico dos pais em instituições de ensino de prestígio, o que tornou possível à egressa o acúmulo de capital escolar.

A prática de leitura foi também uma constante em duas trajetórias sociais. $\mathrm{O}$ hábito cultivado no ambiente doméstico desempenhou um importante papel na construção da imagem formulada por Adélia e Lourdes acerca da importância da escola e ofereceu condições para que alcançassem êxito nos campos em que se inseriram ao longo de seus percursos escolares e carreiras profissionais. Assim como as meninas provenientes de classes sociais abastadas, essas egressas iniciaram na "corrida pelo sucesso escolar" com vantagens que se refletiram por todo o percurso por elas traçados: ambas entraram nos primeiros anos de escolarização dominando com desenvoltura a leitura e a escrita e liam com muita frequência, além de estarem revestidas de um sentimento de valorização do saber escolar que as projetava para o sucesso. Destaca-se também que, ainda que essas egressas não fizessem parte de famílias com volumes elevados de capitais, em ambos os casos encontraram-se condições, a partir do superinvestimento afetivo que a elas era direcionado, para que se apropriassem da herança familiar e superassem a condição social e cultural dos pais.

O estudo do caso dessas trânsfugas permitiu-nos auferir também os limites da condição social feminina na década de 1950 e a influência das alianças matrimoniais no delinear da trajetória social de mulheres detentoras de volumes pouco consideráveis de capitais. Nos três casos analisados a condição social e econômica alcançada pelas egressas devia-se também - e principalmente - ao fato 
de terem casado com homens que angariaram êxito em suas carreiras. Todavia, no caso das ex-alunas Lúcia e Adélia, o casamento figurou também como o mote para que finalizassem os sonhos de concluir um curso universitário ou atuar profissionalmente, o que denuncia casos onde, ainda que houvesse todas as condições e disposições necessárias à transgressão, opta-se pelas escolhas mais palpáveis e condizentes com as condições sócio-familiares.

Por fim, gostaríamos de mencionar o fato de que de um modo mais ou menos intenso as trajetórias dessas egressas examinadas indicam que elas foram ao mesmo tempo trânsfugas de classe social e de gênero. Em dois dos casos colocaram-se também outros aspectos, como o fato de Lourdes e Adélia reproduzirem o ambiente familiar em que foram socializadas e direcionarem seus investimentos e capitais em uma única filha herdeira que foi alvo de investimentos concentrados.

\section{LETÍCIA VIEIRA}

Mestranda no Programa de Pós-Graduação em Educação da Universidade do Estado de Santa Catarina (UDESC).

\section{NORBERTO DALLABRIDA}

Doutor em História Social pela Universidade de São Paulo (USP) com PósDoutorado na Université Rene Descartes (Paris V). Professor efetivo e pesquisador no Curso de Pedagogia e no Programa de Pós-Graduação em Educação (Mestrado e Doutorado) da Universidade do Estado de Santa Catarina (UDESC).

\section{REFERÊNCIAS}

BOURDIEU, Pierre. Razões Práticas: sobre a teoria da ação. CORREAA, Mariza (tradução). Campinas, SP: Papirus, 1996.

BOURDIEU, Pierre. A escola conservadora: as desigualdades frente à escola e à cultura. In: NOGUEIRA, Maria Alice; CATANI, Afrânio (orgs.). Escritos de Educação. Petrópolis, RJ: Vozes, 1998a, p. 39-64.

.O capital social - notas provisórias. In: NOGUEIRA, Maria Alice; CATANI, Afrânio (orgs.). Escritos de Educação. Petrópolis, RJ: Vozes, 1998b, p. 65-69.

. Os três estados do capital cultural. In: NOGUEIRA, Maria Alice; CATANI, Afrânio (orgs.). Escritos de Educação. Petrópolis, RJ: Vozes, 1998c. p. 71-79. 
Alta Costura e Alta Cultura. In: BOURDIEU, Pierre. Questões de Sociologia. Tradução: Miguel Serras Pereira. Lisboa: Fim de Século Edições, Sociedade Unipessoal, Ltda, 2003. p. 205-215.

Perspectiva, 2004

A economia das trocas simbólicas. 5. ed. São Paulo: Horizonte: Autêntica, 2011.

CHARTIER, Roger. O sociólogo e o historiador. Belo

DALLABRIDA, N. Usos sociais da Cultura Escolar Prescrita no Ensino Secundário. Revista Brasileira de História da Educação, v. 11, p. 167-192, 2012.

O público e o privado no Ensino Secundário em Santa Catarina (1945-1961). In: Revista de Educação Pública, n. 42, v. 20, jan/abr 2011. P. 145-157.

JULIA, Dominique. Acultura escolar como objeto histórico. Revista Brasileira de História da Educação. Campinas-SP, n. 1, p. 09-45, jan/jun, 2001.

LAHIRE, Bernard. Sucesso escolar nos meios populares: as razões do improvável. $3^{a}$ impressão. São Paulo: Ática, 2008.

individuais. Porto Alegre: Artmed, 2004.

Retratos Sociológicos: disposições e variações

MARTINI, Estela Maris. Mulheres destinadas ao êxito: Trajetórias Escolares e Profissionais de Ex-alunas do Curso Científico do Colégio Coração de Jesus de Florianópolis (1949-1960). Dissertação: Universidade do Estado de Santa Catarina UDESC. Florianópolis, 2011.

MONTAGNER, Miguel Ângelo. Trajetórias e biografias: notas para uma análise bourdieusiana. In: Revista Sociologias. Porto Alegre, ano 9, $\mathrm{n}^{\circ}$. 17, jan/jun. 2007, p. 240-564.

- CATANI, Afrânio. Uma sociologia da produção do mundo cultural e escolar. In: NOGUEIRA, Maria Alice; CATANI, Afrânio (orgs.). Escritos de Educação. Petrópolis, RJ: Vozes, 1998, p. 7-15.

Questionário 1. Pesquisa "Trajetórias de Egressas do Ensino Secundário em Florianópolis (dec. 1950)”, 2009.

Questionário 2. Pesquisa "Trajetórias de Egressas do Ensino Secundário em Florianópolis (dec. 1950)”, 2009.

Questionário 3. Pesquisa "Trajetórias de Egressas do Ensino Secundário em Florianópolis (dec. 1950)", 2009. 
SOUZA, Rosa Fátima de. História da organização e do currículo no século XX: ensino primário e secundário no Brasil. São Paulo: Cortez, 2008.

VIEIRA, Letícia. Entrevista concedida à Letícia Vieira. Florianópolis, 02 nov. de 2011. Entrevista.

VIEIRA, Letícia. Entrevista concedida à Letícia Vieira. Florianópolis, 20 de jun. 2012a. Entrevista.

VIEIRA, Letícia. Entrevista concedida à Letícia Vieira. Florianópolis, 26 jun. 2012b. Entrevista. 